\title{
Research on Green Energy Internet Planning Model
}

\author{
Kan Pan ${ }^{1}$, Anrui $\mathrm{Li}^{2}$, Zheng Yang ${ }^{1}$, Yongjie Nie ${ }^{1}$, Zhenwei Geng ${ }^{3}$, Junjie Wen ${ }^{2}$, Wentao Liu ${ }^{2}$, Shichen Wang ${ }^{2}$, Hui Chen ${ }^{2}$ \\ and Zuyuan Huang ${ }^{3, *}$ \\ ${ }^{1}$ Electric Power Research Institute, Yunnan Power Grid Co. Ltd, Kunming, China \\ ${ }^{2}$ Key Laboratory in Software Engineering of Yunnan Province, School of Software, Yunnan University, China \\ ${ }^{3}$ Information Center, Yunnan Power Grid Co. Ltd, Kunming, China
}

\begin{abstract}
This paper intends to take power system planning as the main module, while considering the requirements and constraints of natural gas network and transportation network construction and use the energy hub model to analyse the energy transmission and transformation relationship between different networks, to realize the power system, natural gas network, and transportation. Integrated energy system planning for the network. To verify the effectiveness of the proposed PMIES planning method, an improved Garver test system is used for simulation. The system includes a 7-node natural gas network system and a 6node electric test system. We optimized and analysed the simulated system for model research.
\end{abstract}

\section{Introduction}

The integrated energy system is based on a tightly coupled multi-dimensional energy physical system [1], through organic interaction and coordination and optimization of energy generation, distribution, conversion, and consumption, to achieve two-way on-demand transmission of energy [2] and dynamic balanced use [3], thus forming an integrated system of energy production, supply, and marketing [4]. The core of the multidimensional energy physical system is the electric power system, coupled with other energy systems such as the natural gas network system and the transportation network system, and its system scope is highly extensible, which can be system-level or regional-level. With the development of the Energy Internet, the distributed system structure will make the energy system more decentralized [5], so the scope of the system studied in this paper is limited to the terminal multi-energy self-balancing unit, namely SUME. As the proportion of distributed gas generating units and energy storage units in the system continues to increase, the power system's requirements for natural gas networks and transportation networks will also continue to increase. In the planning of integrated energy systems, the combination of power systems, natural gas networks, and transportation networks will continue to increase. Coordinated planning is an important trend. [6]

The basic idea of modelling is: the interface between the transportation network and the power system is electric vehicles and charging devices. According to the number of electric vehicles and the law of charging and discharging behaviour, the simulated charging and discharging load demand and the quota power of the charging device are key input parameters for power system optimization planning; combined with the optimization planning results of the transportation network, the power system optimization model incorporates transportation network parameters and constraints, and performs power supply and grid planning, and clarifies the configuration plan of power components; feeds back the optimization configuration plan of the power system to Transportation network [7], observe whether it meets its model requirements and actual conditions and make corresponding adjustments. At the same time, input the configuration schemes of power system gas generators, DCHP and other components into the natural gas network optimization planning model, plan the gas pipelines, P2G and other facilities; feedback the results of natural gas network optimization planning to the power system, and observe whether it meets its model requirements and reality. If all constraints are met, PMIES realizes integrated energy system planning [8-9].

\section{NATURAL GAS NETWORK FACILITY INVESTMENT PLANNING MODEL}

The supply and demand network of natural gas can be divided into natural gas supply, natural gas transmission, and natural gas load. Among them, the supply sources of natural gas mainly include the regasification of liquefied natural gas at storage stations and pipeline transportation of natural gas stations; the transportation channels of natural gas mainly include gas pipelines and large tankers or ships; natural gas loads include industrial and commercial applications, chemical raw materials, and gas power generation. The role of a natural gas storage station is like the "peak-shaving and valley-filling" of electricity. It stores natural gas when the load is low and releases the natural gas from the storage station to the market when the load is high. In addition, it also plays a certain role. The

\footnotetext{
*Corresponding author: 20182868@qq.com
} 
role of strategic reserves. SUME is a small area system. From the perspective of system economy, it does not have the conditions to configure large storage tanks. Small storage tanks have limited impact on the cost of gas power generation or gas heating. Therefore, this model only considers the gas pipeline network and P2G costs. The gas storage facility is assumed to already exist at each node. Since the multi-energy system is planned together with the power system, the natural gas load mainly considers the natural gas heat load and gas power generation load.

To realize the mutual conversion of energy in SUME, SUME is equipped with a distributed combined heat and power (DCHP) system and power to gas (P2G) facility. To clearly define the boundaries of investment accounting, suppose DCHP is a power generation equipment, which is separately developed in the power system planning model. Therefore, the total cost function of natural gas-related facilities in the natural gas network planning model is: $T C^{g a s}=I C^{g a s}+O C^{g a s}-Z^{g a s}$

$$
\begin{aligned}
& =\sum_{t \in T}\left(\sum_{n \in N} I C^{P 2 G} \cdot \Delta P_{n, t}^{P 2 G}\right)(1+r)^{-t} \\
& +\sum_{t \in T}\left(\sum_{n, m \in N} I C^{\text {pipe }} \cdot l_{n \leftrightarrow m}^{g a s} \cdot z_{n \leftrightarrow m, t}^{\text {pipe }}\right)(1+r)^{-t} \\
& +\sum_{t \in T}\left(\sum_{n \in N} O C^{P 2 G} \cdot U_{n, t}^{P 2 G}\right)(1+r)^{-t} \\
& +\frac{(1+r)^{t}-1}{r \cdot(1+r)^{t} \cdot O C^{\text {pipe }}} \\
& +\sum_{t \in T}\left(p^{g a s} \cdot U_{t}^{\text {net }}\right)(1+r)^{-t} \\
& +\sum_{t \in T}\left(C_{\text {cut }}^{\text {gas }} \cdot U_{t}^{\text {cut }}\right)(1+r)^{-t} \\
& -\sum_{t \in T}\left\{\frac{I C_{t}^{\text {P2G }}}{T^{\text {P2G }}\left[T^{P 2 G}-(T-t)\right]}\right. \\
& \left.+\frac{I C_{t}^{\text {pipe }}}{T^{\text {pipe }}}\left[T^{\text {pipe }}-(T-t)\right]\right\}
\end{aligned}
$$

Where: $T C^{g a s}$ represents the total cost of the natural gas network during the planning period; IC gas represents the total investment cost during the natural gas network planning period; $O C^{\text {gas }}$ represents the total variable cost of the natural gas network; $Z^{\text {gas }}$ Represents the residual value of the investment equipment during the planning period at the end of the planning period; $I C_{t}^{P 2 G}$ and $I C_{t}^{\text {pipe }}$ respectively represent the total investment in electricity-to-gas equipment and pipelines in year $\mathrm{t} ; T^{P 2 G}$ and $T^{\text {pipe }}$ respectively represent the life period of electricity-to-gas equipment and pipelines; $T$ represents the set of planning period years, $t$ represents the $t$-th planning year; $N$ represents the set of natural gas network nodes, including all system nodes through which natural gas passes, and $n$ represents the n-th natural gas network Node; $r$ represents the discount rate; $I C_{n, t}^{P 2 G}$ and $I C_{n, t}^{\text {pipe }}$ respectively represent the investment cost per unit capacity of the electricity-to-gas equipment and the unit length investment cost of the gas pipeline; $\Delta P_{n, t}^{P 2 G}$ represents the capacity of newly installed $\mathrm{P} 2 \mathrm{G}$ devices on node $\mathrm{n}$ in year $\mathrm{t} ; l_{n \leftrightarrow m}^{\text {gas }}$ represents the length of the pipeline to be laid from node $\mathrm{n}$ to node $\mathrm{m} ; z_{n \leftrightarrow m}$ is a boolean variable. When $z_{n \leftrightarrow m}=1$, it means to lay the pipeline from node $n$ to node $m$ in year $t$, otherwise the same. $O C^{P 2 G}$ and $O C^{\text {pipe }}$ represent the variable cost of electricity-to-gas equipment and gas transmission pipelines, respectively. OC $C^{\text {pipe }}$ is slightly affected by the length of the pipeline and the flow of natural gas. Assuming that the annual $O C^{\text {pipe }}$ does not Change, and the transmission loss is also considered in OC $U_{n, t}^{p 2 g}$ represents the total volume of electricity to gas at node $\mathrm{n}$ in year $\mathrm{t} ; p^{\text {gas }}$ represents the natural gas price of the upper-level network; $U_{t}^{\text {net }}$ represents the volume of natural gas purchased from the upper-level network in year $\mathrm{t} ; C_{\text {cut }}^{\text {gas }}$ represents the cost of load reduction when the supply of natural gas is insufficient; $U$ represents the total volume of natural gas load reduction in year $t$.

Like electricity, natural gas must comply with certain physical laws and system constraints during transmission and application, such as the relationship between flow rate, temperature and pressure, node flow balance, and node pressure balance.

\section{ELECTRIC VEHICLE CHARGING FACILITY INVESTMENT PLANNING MODEL}

In SUME, electric vehicles are especially important mobile energy storage components, as well as a key node for the coupling of transportation networks and power systems. The development of electric vehicles enables signals in the field of electric energy such as electricity prices to become one of the important measures to guide the layout and operation of the transportation network. The connection points between electric vehicles and the power system are mainly various types of charging and swapping stations. The layout of the connection points will directly affect the comprehensive economic benefits and operating efficiency of the power system and transportation network. Therefore, it is particularly important to consider the location and capacity of electric vehicle charging and swapping stations in the planning of the integrated energy system.

\subsection{The charging demand of electric vehicles}

The slow charging station is the main energy supply facility for electric vehicles, and the fast-charging station is a good supplementary facility for the slow charging station, which can provide charging services for more electric vehicles. Due to the high cost of substations, they are generally only targeted at some public special vehicles. Therefore, this article mainly considers the location and capacity of slow charging stations and fast charging stations. The first to solve the problem of location and capacity of charging stations is to calculate the charging demand of electric vehicles. Before calculating the charging demand of electric vehicles, the following 
assumptions need to be clarified: (1) The driving range of the battery under the current technical conditions is SD_0. Ignore the difference in battery capacity of different types of vehicles, that is, SD 0 has nothing to do with the vehicle type; (2) Based on the current power battery technology level, the battery cycle life is short, the depreciation cost is high, and the economy is poor. If you repeatedly use high currents above $3 \mathrm{C}$ Fast charging of the battery will significantly shorten the battery life and cause the economic efficiency of electric vehicles to deteriorate. Therefore, the charging station is set to be constructed on the principle of "slow charging as the main and fast charging as auxiliary".

According to the above assumptions, the total charging demand of electric vehicles in SUME can be calculated by formula (2), which provides capacity constraint data for the location and capacity of subsequent charging stations.

$$
q^{E V}=\sum_{h \in H} q_{h}^{E V}=\sum_{h \in H} h\left(e \cdot \frac{y_{h}}{S D_{0}}\right)
$$

In the formula, $q^{E V}$ represents the daily maximum charging frequency demand; $q_{h}^{E V}$ represents the charging frequency of electric vehicles in $h$ period; $e$ represents the possession of electric vehicles; $y$ represents the average driving range of electric vehicles in $h$ period; $H$ represents the set of all operating periods, and $h$ represents the h-th period.

\subsection{Charging station planning and configuration}

Queuing theory is a mathematical theory that studies the reasonable coordination of the relationship between "demand" and "service". This section uses the principles and methods of queuing theory to construct a queuing model that can reflect the characteristics of the system and studies the operating indicators such as the length of the charging fleet in the system and the waiting time. When configuring charging facilities, the queue length and waiting time of electric vehicles are especially important system constraints.

It is a random process for an electric vehicle driving on the road to find that the battery is insufficient and need to be charged. To study the charging work of the charging station, it is necessary to clarify the law of occurrence of electric vehicle charging. According to experience, it can be known that the charging demand generation process meets the following three characteristics:

(1) The time interval between two cars' charging demand can be regarded as a process with no aftereffect, that is, the number of customers arriving in a nonoverlapping time period is independent of each other;

(2) For a sufficiently small time interval $\Delta h$, in the time interval $[h, h+\Delta h]$, the probability that an electric vehicle will arrive has nothing to do with time $h$, and Only proportional to the length of the time interval;

(3) For a sufficiently small time interval $\Delta h$, the probability of two or more electric vehicles arriving in the time interval $[h, h+\Delta h]$ can be Negligible, this shows that the time of arrival of electric vehicles is different, and it is an independent event.

The above three characteristics are in line with the characteristics of Poisson distribution, and Poisson flow can be used to describe the law of electric vehicles generating charging demand. If the electric vehicle charging demand is a Poisson flow, the time interval $T$ between the successive arrivals of two electric vehicles obeys a negative exponential distribution. Therefore, the demand trigger point of electric vehicles in SUME, the charging capacity of charging stations, and the queuing status of electric vehicles can be assumed and restricted as follows:

(1) The charging time of each vehicle obeys a negative exponential distribution.

(2) A charging device can only accept the charging request of an electric car at the same time, and there is no difference between the charging devices in the charging station, which is a multi-channel service system with limited system capacity.

(3) The number of electric vehicles waiting in line should not exceed a certain number.

(4) The average waiting time for electric vehicles to be charged should not exceed a certain time, otherwise it will cause excessive waiting time and affect the travel of customers.

Through the above analysis, the charging system mode is $\mathrm{M} / \mathrm{M} / \mathrm{C}$, that is, the Poisson input, negative exponential service time distribution, and the waiting system queuing model of $C$ service stations (ie, charging devices). If the charging devices can work at the same time and are independent of each other, and the average service rate is all Igamma (that is, the inverse of the average charging time), the average service rate of the entire charging station is shown in formula (3):

$$
\Gamma= \begin{cases}C \cdot \gamma & \text { if } C \geq n \\ e \cdot \gamma & \text { if } C<n\end{cases}
$$

Formula (4) shows the maximum arrival rate $\lambda_{i}^{\prime}$ of a vehicle to be charged in a certain period, that is, the reciprocal of the minimum time interval between the arrival of electric vehicle users, which is an important basis for the number of charging devices installed at the node.

$$
\lambda_{i}^{\prime}=\max _{h \in H}\left\{\lambda_{i, h} \mid \lambda_{i, h}=\frac{q_{h}^{E V} \cdot \tau_{h} \cdot f_{i, h}^{E V}}{\sum_{h \in H} \tau_{h} \sum_{i \in I} f_{i, h}^{E V}}, h \in H\right\}
$$

The formula (5) characterizes the charging power of the electric vehicle in a certain period at node $i$.

$$
P_{i, h}^{E V}=\frac{\lambda_{i, h}}{\gamma} \cdot p^{E V} \quad \forall h \in H, i \in I
$$

In the formula: $I$ represents the node set of the power network, and $i$ represents the $\mathrm{i}$-th node. The location of the root charging station is the connection between the transportation network and the power network. Therefore, the nodes of the electric vehicle charging network are directly labelled with the power system node to facilitate subsequent calculations; $\lambda_{i}^{\prime}$ indicates that the electric vehicle at node $i$ is the largest Arrival rate; $\lambda_{i, h}$ represents the average arrival rate of electric vehicles at 
node $i$ in time period $h ; f$ represents the total flow of electric vehicles at node $i$ in time period $h ; \tau_{h}$ represents the average utilization rate of electric vehicles in time period $h ; p^{E V}$ represents the charging power of a single electric vehicle.

For electric vehicle users, how to charge more conveniently and quickly without affecting their normal use of the vehicle is particularly important. The fastcharging method generally occurs during the use of the vehicle and has relatively high requirements for charging time and queuing time; the slow charging method generally occurs when the vehicle is idle, and the slow charging time is long, and the user cannot wait for a long time for the previous vehicle to be charged. Charge it again when finished. The core factor affecting the service level of charging stations is the average charging waiting time of users. Therefore, the number of charging devices at the charging station is configured according to the user's maximum allowable charging waiting time $\Delta h_{\max }$ during peak traffic, as shown in formula (6)-formula (9):

$$
\begin{gathered}
\min P_{0 i}^{E V}=C_{i} p^{E V} \\
\text { s.t. } \Delta h_{i}^{\prime} \leq \Delta h_{\max } \\
\Delta h_{i}^{\prime} \approx \max _{h \in H} \Delta h_{i, h}^{\prime}=\left[\frac{\left(C_{i} \cdot \tau\right)}{\lambda_{i}^{\prime} \cdot\left(C_{i}\right) ! \cdot(1-\tau)^{2}} \operatorname{Pr}_{0 i}\right] \\
\operatorname{Pr}_{0 i}=\left[\sum_{R=0} \frac{\left(C_{i} \cdot \tau\right)^{R}}{R !}+\frac{\left(C_{i} \cdot \tau\right)^{C_{i}}}{C_{i} !(1-\tau)}\right]^{-1} \quad \forall i \in I \\
\tau \tau^{\prime}=\frac{\lambda_{i}{ }^{\prime}}{C_{i} \gamma} \forall i \in I
\end{gathered}
$$

The focus of the above model lies in the decision variable $C_{i}$. Through model calculation, two sets of key vectors $C=\{C 1, C 2 \ldots C i\}$ and $p^{E V}$ can be obtained, which respectively represent the number of charging devices installed at each node and the number of charging devices. The total capacity, and these data are the basic data for calculating the total cost of the transportation network, and it is also one of the decision variables for the coordinated planning of the integrated energy system including the power system, the transportation network, and the natural gas network. The cost function of electric vehicle-related facilities in the transportation network is:

$$
\begin{aligned}
T C^{E V}= & I C^{E V}+O C^{E V}-Z^{E V} \\
= & \sum_{t \in T}\left(\sum_{i \in I} I C^{E V} \cdot \Delta C_{i, t}\right)(1+r)^{-t} \\
& +\sum_{t \in T}\left(\sum_{i \in I} O C^{E V} \cdot C_{i, t}\right)(1+r)^{-t} \\
& -\sum_{t \in T}\left\{\frac{I C_{t}^{E V}}{T^{E V}}\left[T^{E V}-(T-t)\right]\right\}
\end{aligned}
$$

Where: $T C^{E V}, I C^{E V}, O C^{E V}$ and $Z^{E V}$ respectively represent the total cost, total investment cost, total variable cost and the end of the new investment equipment planning period during the transportation network planning period The residual value of; $\Delta C_{i, t}$ represents the number of newly added charging devices at node $i$ in year $t ; C_{i, t}$ represents the number of charging devices already operating at node $i$ in year $t ; I C_{t}^{E V}$ indicates the total investment of the charging device in year $t ; T^{E V}$ indicates the life span of the charging device.

\section{INTEGRATED ENERGY SYSTEM COORDINATION PLANNING MODEL}

On the energy supply side, SUME includes multiple types of DG units, natural gas $\mathrm{P} 2 \mathrm{G}$ devices, mobile energy storage (electric vehicles), energy storage components, etc. (due to regional limitations, large generator sets are not considered, and the lack of electricity is provided by the upper-level grid); On the energy transmission side, SUME includes power transmission lines, gas pipelines, transportation networks, etc.; on the energy load side, SUME includes electrical loads, natural gas loads, thermal loads, etc. The thermal load is mainly provided by the transformation of electric energy and natural gas at the terminal, so it does not Consider the heating pipeline separately.

The model proposed in this paper is aimed at minimizing the comprehensive cost of the system within the planning scope, while considering the basic requirements and safety requirements of the physical operation of the power system, natural gas network, and transportation network. The overall system cost includes the investment cost and variable cost of natural gas network facilities, the investment cost and operation and maintenance cost of charging station facilities, the investment cost and variable cost of power generation and grid facilities, and the purchase cost of natural gas and electricity from the upper-level network. To accurately reflect the time value of costs, all costs and expenses are expressed in the form of the initial annual present value of the plan.

$$
\min T C_{\text {total }}=T C^{g a s}+T C^{E V}+T C^{e l e}
$$

In the formula: $T C_{\text {total }}$ represents the total comprehensive cost during the planning period of the integrated energy system; $T C^{\text {ele }}$ represents the total cost during the planning period of the power system.

$$
\begin{aligned}
T C^{e l e}= & \sum_{t \in T}\left\{\left[\sum_{i \in I} \sum_{g \in G}\left(I C_{g}^{D G} \cdot \Delta P_{g, i, t}^{D G}\right)\right.\right. \\
& \left.\left.+\sum_{i \in I}\left(O C_{g}^{D G} \cdot P_{g, i, t}^{D G}\right)\right](1+r)^{-t}\right\} \\
& +\sum_{t \in T}\left\{\left[\sum_{i, j \in I \exists(i, j)}\left(I C_{i j}^{L} \cdot z_{i j, t}^{L}\right)+O C^{L} \cdot P_{i j, t}^{L}\right](1\right. \\
& \left.+r)^{-t}\right\} \\
& +\sum_{t \in T}\left\{\left[\sum_{i \in I}\left(I C^{S} \cdot \Delta P_{i, t}^{S}+O C^{S} \cdot q_{i, t}^{S}\right)\right](1+r)^{-t}\right\}
\end{aligned}
$$




$$
\begin{gathered}
+\sum_{t \in T}\left[\sum_{b \in B}\left(c^{D R} \cdot P_{b, t}^{D R} \cdot \Delta h_{b}+c^{c u t} \cdot Q_{b, t}^{c u t}\right)(1\right. \\
\left.+r)^{-t}\right] \\
+\sum_{t \in T}\left[\left(p^{e l e} \cdot Q_{t}^{\text {net }}\right)(1+r)^{-t}\right] \\
-\sum_{w \in W} \frac{I C_{w}^{e l e}}{T_{w}}\left[T_{w}-\left(T-t_{w}\right)\right]
\end{gathered}
$$

Where: $G$ represents the set of power generation types of DG, $g$ represents the g-th power generation type of DG; $I C_{g}^{D G}$ represents the unit capacity investment cost of DG units of power generation type $g ; \Delta P_{g, i, t}^{D G}$ represents the newly added DG unit capacity of power generation type $g$ in node $i$ in the $t$ year; $O C_{g}^{D G}$ represents the unit capacity operating cost of the DG unit of power generation type $g ; P_{g, i, t}^{D G}$ represents the actual operation of power generation type $g$ in node $i$ in the $t$ year Capacity; $I C_{i j}^{L}$ represents the investment and construction cost of the line between nodes $i$ and $j ; z_{i j, t}^{L}$ represents a Boolean variable, $=1$ represents that there is capacity expansion between node $i$ and node $j$ in year $t$, and vice versa; $O C^{L}$ represents line unit capacity operation Cost; $P_{i j, t}^{L}$ represents the actual operating capacity between node $i$ and node $j$ in year $t ; I C^{S}$, $O C^{S}$ represent the unit capacity investment cost and operating cost of the energy storage unit respectively; $\Delta P_{i, t}^{S}$ represents the newly added energy storage capacity in node $i$ in the $t$ year; $q_{i, t}^{S}$ represents the total circulating power between the system and the energy storage unit in node $i$ in the $t$ year; $B$ is the set of load segments, $\quad B=\left\{b \mid b=b_{x}, x=1,2,3 \ldots\right\} \quad, \quad b_{x}$ represents the xth load segment. For the convenience of calculation, assume that the load segment set $B$ and the time segment set $H$ in the electric vehicle module are divided in the same time span; $c^{D R}$ represents the unit capacity cost of the system to implement demand response; $P_{b, t}^{D R}$ means that the load segment $b$ in the thear is reduced by demand response $z_{b, t}$ are boolean variables, $=1$, it means that load segment $b$ has achieved load reduction in year $t$, and vice versa; $\Delta h_{b}$ means response duration; $c^{\text {cut }}$ means the unit compensation paid to the user to directly reduce the load of the user Cost, assuming that it is replenished in the unit of electricity; $Q_{b, t}^{c u t}$ represents the user electricity directly cut by load segment $b$ in the $\mathrm{t}$-th year; $z_{b, t}$ is a Boolean variable, and $=1$ means the $\mathrm{t}$-th year Load segment $b$ has achieved direct load reduction, and vice versa; $p^{\text {ele }}$ represents the power purchase cost from the upper-level grid; $Q_{t}^{\text {net }}$ represents the total power purchase from the upper-level grid in year $t ; W$ represents the collection of all equipment in the system, $\quad W=\left\{w \mid w=W_{x}, x=1,2,3 \ldots\right\} \quad, \quad w_{x}$ represents the wth device; $T_{w}$ represents the life span of the device $w ; t_{w}$ represents the year the device was put into use, that is, the number of years from the initial year of the planning period.

In formula (12), the first term represents the investment cost of new DG units in the system during the planning period and the operation and maintenance costs of all units; the second term represents the comprehensive cost of the system's transmission lines, including expansion investment costs and operation and maintenance costs; The third item represents the total cost of the energy storage unit in the system, including capacity investment costs and operation and maintenance costs; the fourth item is the system outage cost, which is composed of demand response costs $c^{D R}$ and load shedding costs ${ }^{c u t}$; the fifth item is SUME from the upper grid The sixth item is the residual value of new facilities in the system at the end of the planning year.

In addition, to ensure the safety and stability of the system, the planning and operation of SUME also need to meet the following constraints:

(1) DG capacity constraints

The active power and reactive power of the DG unit are restricted by its maximum and minimum capacity, and the installable DG capacity of node $i$ is also restricted.

$$
\begin{gathered}
P_{i, 0}^{D G}+\sum_{t \in T} \Delta P_{i, t}^{D G} \leq P_{i, \max }^{D G} \\
P_{g}^{\text {min }} \leq P_{g}^{D G} \leq P_{g}^{\max }
\end{gathered}
$$

(2) Line capacity constraints

Due to the limitation of space resources, the transmission channel between nodes can bear the limited line capacity, which is a constraint to be considered for line upgrades.

$$
\begin{gathered}
P_{i j, 0}^{L}+\sum_{t \in T} \Delta P_{i j, t}^{L} \leq P_{i j, \max }^{L(i, j)(i, j)} \\
\Delta P_{i j, t}^{L} \leq M z_{i j}^{L} \quad \forall(i, j) \in I
\end{gathered}
$$

(3) Power flow constraints

$$
\begin{gathered}
P_{i}=\left|V_{i}\right| \sum_{j \in I}\left|V_{j}\right|\left(G_{i j} \cos \theta_{i j}+A_{i j} \sin \theta_{i j}\right) \\
\forall(i, j) \in I: \exists(i, j) \\
Q_{i}=\left|V_{i}\right| \sum_{j \in I}\left|V_{j}\right|\left(G_{i j} \sin \theta_{i j}-A_{i j} \cos \theta_{i j}\right) \\
\forall(i, j) \in I: \exists(i, j)
\end{gathered}
$$

In the formula: $P_{i}, Q_{i}$ and $\left|V_{i}\right|$ represent the active power, reactive power injection and voltage amplitude of node $i$ under normal conditions; $G_{i j}$ and $A_{i j}$ represent the system conduction under normal conditions. The real and imaginary parts of the nano matrix; $\theta_{i j}^{v}$ represents the voltage phase angle difference between node $i$ and node $j$.

(4) Voltage constraints

$$
V_{\min } \leq V_{i} \leq V_{\max }
$$

In the formula: $V_{i}$ represents the node voltage of node $i ; V_{\min }$ and $V_{\max }$ represent the lower limit and upper limit of the allowable voltage fluctuation of the system node, respectively.

(5) Energy storage constraints

Due to its own technical conditions and economic constraints, the energy storage in PMIES adopts energy storage units with medium capacity and relatively mature 
technology. In actual operation, the charge and discharge capacity and rate of energy storage must meet the following constraints:

$$
\begin{gathered}
S O C_{i, b}^{S}=S O C_{i, b-1}^{S}+\left[\left(q_{i, b}^{c} / \xi^{c}-\xi^{d} q_{i, b}^{d}\right) / P_{i}^{S}\right] \\
\forall b \in B, i \in I
\end{gathered}
$$

\section{SIMULATION ANALYSIS}

PMIES is an optimization model containing multiple main modules. Among them, natural gas pipeline airflow equations are non-linear equations, which can be processed by incremental piecewise linearization, thereby transforming the model into a mixed integer linear optimization problem that is relatively easy to solve. To verify the effectiveness of the proposed PMIES planning method, an improved Garver test system is used for simulation. The system includes a 7-node natural gas network system and a 6-node electric test system, as shown in Figure 1. Among them, the natural gas network system includes 2 natural gas production nodes (including P2G facilities) and 5 natural gas load nodes. For basic system data of the power system, see Table 1 and Table 2.

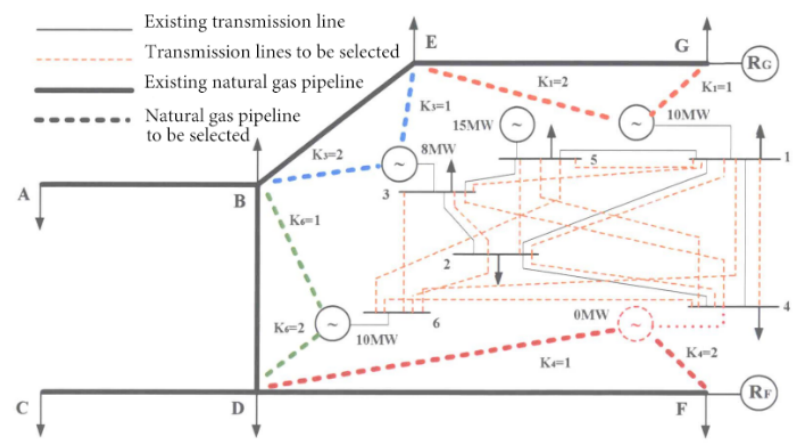

Fig. 1. Garver test system diagram.

\begin{tabular}{|c|c|c|c|c|}
\hline & $\begin{array}{c}\text { Line } \\
\text { endpoint }\end{array}$ & $\begin{array}{c}\text { Resistance } \\
\text { M } \Omega\end{array}$ & $\begin{array}{c}\begin{array}{c}\text { Cost of } \\
\text { investment }\end{array} \\
(104 \\
¥ \mathrm{KM}) \\
\end{array}$ & $\begin{array}{c}\text { Capacity } \\
\text { MW }\end{array}$ \\
\hline \multirow{6}{*}{$\begin{array}{l}\text { Existing } \\
\text { lines }\end{array}$} & $1-2$ & 0.1 & 0 & 20 \\
\hline & $1-4$ & 0.15 & 0 & 15 \\
\hline & $1-5$ & 0.05 & 0 & 20 \\
\hline & $2-3$ & 0.05 & 0 & 20 \\
\hline & $2-4$ & 0.1 & 0 & 20 \\
\hline & $3-5$ & 0.05 & 0 & 30 \\
\hline \multirow{10}{*}{$\begin{array}{l}\text { Lines to } \\
\text { be } \\
\text { selected } \\
\text { for } \\
\text { expansi } \\
\text { on }\end{array}$} & $1-2$ & 0.1 & 40 & 20 \\
\hline & $1-3$ & 0.09 & 38 & 20 \\
\hline & $1-4$ & 0.15 & 60 & 15 \\
\hline & $1-5$ & 0.05 & 20 & 20 \\
\hline & $1-6$ & 0.17 & 48 & 10 \\
\hline & $2-3$ & 0.05 & 20 & 20 \\
\hline & $2-4$ & 0.1 & 40 & 20 \\
\hline & $2-5$ & 0.08 & 31 & 20 \\
\hline & $2-6$ & 0.08 & 30 & 20 \\
\hline & $3-4$ & 0.15 & 59 & 12 \\
\hline
\end{tabular}

Table 1. Transmission line data of the test system.

\begin{tabular}{|l|l|l|l|}
$3-5$ & 0.05 & 20 & 20 \\
\hline $3-6$ & 0.12 & 48 & 20 \\
\hline $4-5$ & 0.16 & 63 & 10 \\
\hline $4-6$ & 0.08 & 30 & 20 \\
\hline $5-6$ & 0.15 & 70 & 25 \\
\hline
\end{tabular}

Table 2. Power node data of the test system (initial year).

\begin{tabular}{|c|c|c|c|}
\hline Node & $\begin{array}{c}\text { Maximum } \\
\text { installable DG } \\
\text { capacity } \\
\text { MW }\end{array}$ & $\begin{array}{c}\text { Existing } \\
\text { capacity } \\
\text { MW }\end{array}$ & $\begin{array}{c}\text { Node load } \\
\text { MW }\end{array}$ \\
\hline 1 & 60 & 20 & 22 \\
\hline 2 & 30 & 0 & 9 \\
\hline 3 & 40 & 18 & 15 \\
\hline 4 & 20 & 0 & 12 \\
\hline 5 & 40 & 20 & 15 \\
\hline 6 & 30 & 15 & 10 \\
\hline
\end{tabular}

Assuming that each electric car is charged with $20 \mathrm{~kW} / \mathrm{h}$ in a single time, it takes 10 hours and 0.5 hours to fully charge through the slow charging and fast charging devices, respectively. The average utilization rate of electric vehicles is 0.3 , and the maximum utilization rate is 0.8. In SUME, slow charging is the main one. The fastcharging device is $30 \%$ of the slow charging. The charging power of a single slow charging device is $14 \mathrm{~kW}$, and the charging power of a fast-charging device is $60 \mathrm{~kW}$. A single node can install no more than 100 devices. According to the number of electric vehicles, the maximum available daily charging frequency is 350 times. The operating characteristic parameters of the power generation and energy storage components in the test system are shown in Table 3 . The charge and discharge efficiency of energy storage is $75 \%$, the maximum discharge rate is $0.5 \mathrm{C}$, and the upper and lower limits of SOC are [0.1-0.95]. The service life of power components is 20 years. In addition, the system load growth rate is set to $5 \%$, the existing power generation capacity is nonDREG power generation type, the planning period is 20 years, the node voltage fluctuation range is $0.95-1.05 \mathrm{pu}$, and the discount rate is 0.06 . The demand response cost $c^{D R}$ is $725 \$ / \mathrm{MW} \cdot \mathrm{h}$, and the load reduction cost $c^{c u t}$ is $870 \$ / \mathrm{MW} \cdot \mathrm{h}$. The sales price of the higher-level grid refers to the average price of industry and commerce in a certain province of my country, which is $0.11 \$ / \mathrm{kW} \cdot \mathrm{h}$ in US dollars. To ensure the reliability of the system, the load involved in demand response and the load directly reduced shall not exceed $10 \%$ and $5 \%$.

Table 3. Operating characteristic parameters of power generation/energy storage components.

\begin{tabular}{|c|c|c|c|c|c|}
\hline $\begin{array}{c}\text { Componen } \\
\text { t type }\end{array}$ & $\begin{array}{c}\text { Unit } \\
\text { capac } \\
\text { ity } \\
\text { MW }\end{array}$ & $\begin{array}{c}\text { Varia } \\
\text { ble } \\
\text { costs } \\
\mathbf{\$} / \mathbf{M} \\
\text { W.h }\end{array}$ & $\begin{array}{c}\text { Cost of } \\
\text { investm } \\
\text { ent } \\
\mathbf{\$} / \mathbf{K W}\end{array}$ & $\begin{array}{c}\text { Forced } \\
\text { outage } \\
\text { rate } \\
\mathbf{\%}\end{array}$ & $\begin{array}{c}\text { Planned } \\
\text { outage } \\
\text { rate } \\
\mathbf{\%}\end{array}$ \\
\hline $\begin{array}{c}\text { Wind } \\
\text { power }\end{array}$ & 0.75 & 7.25 & 1220 & 1.8 & 1.2 \\
\hline PV & 0.5 & 12.32 & 1180 & 2.5 & 1.6 \\
\hline
\end{tabular}




\begin{tabular}{|c|c|c|c|c|c|}
$\begin{array}{c}\text { Distributed } \\
\text { gas }\end{array}$ & 1.5 & 27.45 & 530 & 15 & 7 \\
\hline $\begin{array}{c}\text { Biomass } \\
\text { power } \\
\text { generation }\end{array}$ & 2 & 17.45 & 1520 & 16 & 8 \\
\hline DCHP & 1 & 24.64 & 880 & 12 & 6 \\
\hline $\begin{array}{c}\text { Energy } \\
\text { storage }\end{array}$ & $\begin{array}{c}1000 \\
\text { A.h }\end{array}$ & 11.6 & 260 & - & - \\
\hline
\end{tabular}

As shown in Figure 2, in the improved Garver test system, the 7 nodes of the natural gas network (with the letter AG as the node label) are separated from the power system in the initial year of planning, and the 7 nodes of the natural gas network have 6 pipelines through. , Respectively: Pipe 1, A $\rightarrow$ B, $1800 \mathrm{Nm}^{3} / \mathrm{hr}$; Pipe 2, B $<->$ D, $520 \mathrm{Nm}^{3} / \mathrm{hr}$-psia; Pipe $3, \mathrm{~B}<->$ E, $560 \mathrm{Nm}^{3} / \mathrm{hr}$-psia; Pipe 4 , $\mathrm{C}<->\mathrm{D}, 2600 \mathrm{Nm}^{2} / \mathrm{hr}$-psia; Pipe 5, D<->F, 640Nm²/hr-psia; Pipe 6, E <->G, $700 \mathrm{Nm}^{3} / \mathrm{hr}$-psia. Among them, the natural gas distribution station operation data of node A-G is shown in Table 4. From the formula (2), the actual flow rate of natural gas pipelines is related to factors such as gas specific gravity, friction coefficient, and pipeline diameter. It is known that the proportion of natural gas is 0.5548 and the Manning coefficient is 0.009 . The relationship between the flow rate of the pipeline to be erected and the diameter and length is shown in Table 5. The diameter of the pipeline is positively correlated with the investment cost, as shown in Table 6 . The price of natural gas refers to the price of industrial gas, which is $0.46 \$ / \mathrm{m}^{3}$.

Table 4. Operating data of the distribution station of each node of natural gas.

\begin{tabular}{|c|c|c|c|c|c|}
\hline $\begin{array}{c}\text { Node } \\
\text { Diversion } \\
\text { Station }\end{array}$ & $\begin{array}{c}\text { Diversion } \\
\text { station type }\end{array}$ & $\begin{array}{c}\text { Flow } \\
\text { NM } \\
\mathbf{3} / \mathbf{h r}\end{array}$ & $\begin{array}{c}\text { Press } \\
\text { ure } \\
\text { psia }\end{array}$ & $\begin{array}{c}\text { Press } \\
\text { ure } \\
\text { MIN }\end{array}$ & $\begin{array}{c}\text { Press } \\
\text { ure } \\
\text { MA } \\
\text { X }\end{array}$ \\
\hline A & $\begin{array}{c}\text { Constant } \\
\text { current }\end{array}$ & 800 & - & 75 & 200 \\
\hline B & $\begin{array}{c}\text { Constant } \\
\text { current }\end{array}$ & 800 & - & 120 & 200 \\
\hline C & $\begin{array}{c}\text { Constant } \\
\text { current }\end{array}$ & 800 & - & 75 & 200 \\
\hline D & $\begin{array}{c}\text { Constant } \\
\text { current }\end{array}$ & 800 & - & 120 & 200 \\
\hline E & $\begin{array}{c}\text { Constant } \\
\text { current }\end{array}$ & 800 & - & 120 & 200 \\
\hline F & $\begin{array}{c}\text { Constant } \\
\text { current }\end{array}$ & 800 & - & 120 & 200 \\
\hline G & $\begin{array}{c}\text { Constant } \\
\text { pressure }\end{array}$ & - & 200 & 75 & 200 \\
\hline
\end{tabular}

Table 5. Type and capacity of natural gas pipeline to be selected.

\begin{tabular}{|c|c|c|c|c|c|c|c|}
\hline $\begin{array}{c}\text { Diameter } \\
\text { Length }\end{array}$ & $\mathbf{6}$ & $\mathbf{8}$ & $\mathbf{1 0}$ & $\mathbf{1 2}$ & $\mathbf{1 6}$ & $\mathbf{2 0}$ & $\mathbf{2 4}$ \\
\hline 2 & 0.44 & 0.57 & 0.93 & 1.37 & 2.21 & 3.75 & 5.17 \\
\hline 4 & 0.39 & 0.4 & 0.75 & 1.1 & 2.06 & 3.4 & 4.86 \\
\hline 6 & 0.32 & 0.33 & 0.6 & 0.93 & 1.7 & 3.06 & 4.6 \\
\hline 8 & - & 0.3 & 0.5 & 0.8 & 1.45 & 3.67 & 4.23 \\
\hline 10 & - & - & 0.4 & 0.7 & 1.3 & 2.4 & 3.9 \\
\hline 12 & - & - & - & 0.65 & 1.2 & 2.15 & 3.45 \\
\hline 14 & - & - & - & - & 1.05 & 2 & 3.2 \\
\hline 16 & - & - & - & - & - & 1.85 & 3.05 \\
\hline 18 & - & - & - & - & - & - & 2.8 \\
\hline
\end{tabular}

Table 6. Unit investment cost of different diameter pipes.

\begin{tabular}{|c|c|c|c|c|c|c|c|}
\hline Pipe diameter & 6 & 8 & 10 & 12 & 16 & 20 & 24 \\
\hline $\begin{array}{c}\text { Cost of investment } \\
\text { 104\$/km }\end{array}$ & 21 & 28 & 47 & 68 & 112 & 183 & 258 \\
\hline
\end{tabular}

\section{OPTIMIZATION RESULTS AND ANALYSIS}

In the test system, the coupling interface between the power system and the natural gas system is mainly $\mathrm{P} 2 \mathrm{G}$ equipment, distributed gas-fired units and DCHP. In addition, it is also equipped with certain gas storage equipment (the proportion is small, not reflected in the model). The newly added gas pipelines are mainly distributed gas generators and DCHP gas supply. When the gas supply is insufficient, it is provided by gas storage or energy storage equipment; when the electrical load is low, the surplus electricity can be stored through P2G equipment or meet the gas load.

Through simulation, the planned Garver system structure is shown in Figure 2. Four transmission lines have been added: Line 1-4, Line 2-3, Line 3-5, Line 3-6. Gas transmission pipelines are added on the original basis. 9 lines: K1-K9, four of which are connected to power node 1 , node 3 , node 4 , and node 6 , respectively. The newly added generator sets, and energy storage configuration of each node are shown in Figure 3.

As can be seen from Figures 2 and 3, as the load of each node increases, 6 power nodes have new installed capacity, of which nodes $1,3,4$, and 6 are equipped with gas generators and DCHP, so they are connected to the gas transmission. The pipe is connected to it. From the perspective of DG type, the total new capacity of the system is $108.75 \mathrm{MW}$, of which the distributed gas turbine assembly capacity is the largest, reaching $27.59 \%$; wind power is the second, 24.14\%; the DCHP is affected by the heat load with the smallest proportion of $13.79 \%$. From the point of view of node configuration, node 4 has no power generation capacity allocated in the initial year, so the maximum new capacity is $27.75 \mathrm{MW}$, which is $25.52 \%$ of the total new capacity; the load of node 2 is relatively low, and it is similar to nodes $1,3,4,5$ are all interconnected, so the newly added capacity of the configuration is the smallest, $11 \mathrm{MW}$; the DREG penetration rate of each node is more than $35 \%$ of the total capacity of the system (including the existing capacity in the initial year).

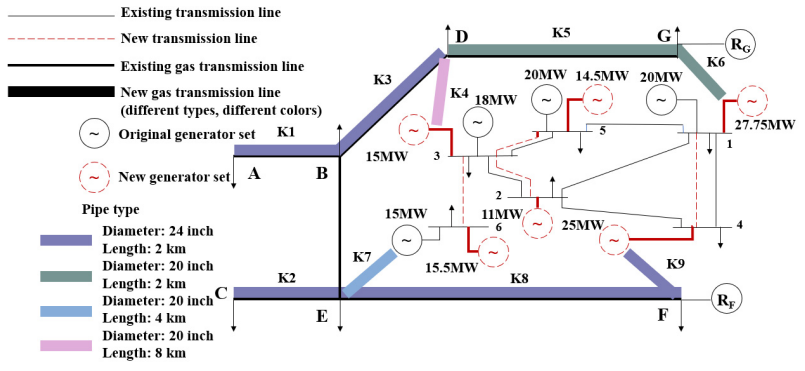

Fig. 2. Planning results of the test system. 


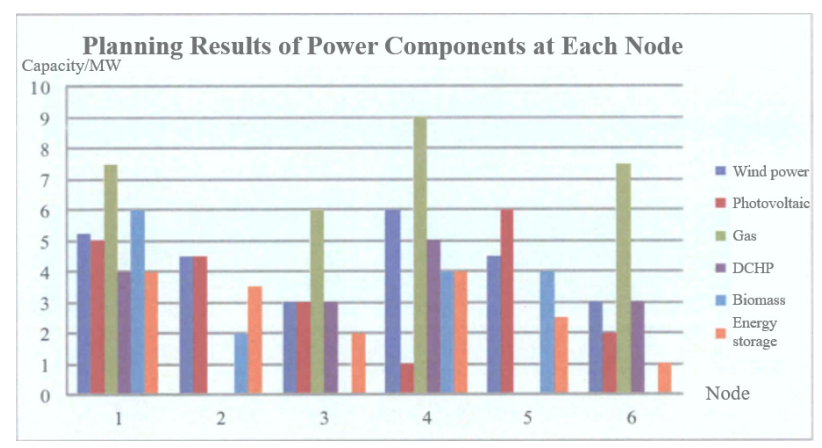

Fig. 3. Planning results of power components at each node.

For the two modules of natural gas network and electric vehicle charging facilities, some intermediate data were extracted.

The average flow of the channels between the natural gas nodes, the pressure of each node in the natural gas network, and the configuration of the charging devices of each node in the transportation network are extracted. Among them, some data of the natural gas network are shown in Table 7. At the end of the plan, the absolute pressures of the seven natural gas nodes were all within the allowable range. The average flow rate was the natural gas channel $\mathrm{C}$ to $\mathrm{D}$, reaching $4200 \mathrm{Nm}^{2} / \mathrm{hr}$ (including the original pipeline flow rate). Channel $\mathrm{B} \rightarrow \mathrm{D}$ is the deployment channel of the upper and lower sides of the natural gas channel. From the flow data, the upper channel supplemented the lower channel with a flow rate of $560 \mathrm{Nm}^{2} / \mathrm{hr}$ at the end of the plan. In the case of channel C-D with the maximum flow, the lower channel also needs the support of the upper channel, indicating that the gas consumption of node 4 and node 6 is relatively large. This phenomenon is also consistent with our planning results: Nodes 4 and 6 are equipped with a total of $24.5 \mathrm{MW}$ of gas-fired units (including distributed gas-fired units and DCHP), accounting for about $60 \%$ of the total gas-fired units. As for the transportation network, there are charging devices at six power nodes. According to calculations, the system is equipped with 453 slow charging devices and 120 fast charging devices; the maximum charging load of the transportation network is $13.54 \mathrm{MW}$, the average charging load is $7.36 \mathrm{MW}$, the maximum reverse transmission load is $-5.20 \mathrm{MW}$, and the average transmission load- $3.73 \mathrm{MW}$.

Table 7. Natural gas node flow and pressure (the end of the plan).

\begin{tabular}{|c|c|c|c|c|}
\hline Starting node & End node & $\begin{array}{c}\text { Average flow } \\
\mathbf{N m}^{\mathbf{3}} \mathbf{h r}\end{array}$ & Node & Pressure \\
\hline A & B & 4000 & A & 90.36 \\
\hline B & E & 3440 & B & 120.06 \\
\hline B & D & 560 & C & 77.19 \\
\hline C & D & 4200 & D & 120.06 \\
\hline D & F & 2750 & E & 173.32 \\
\hline E & G & 1950 & F & 149.03 \\
\hline- & - & - & G & 200 \\
\hline
\end{tabular}

In addition, according to the calculation of the planning results, the comprehensive costs of seven key power components such as wind power, DCHP, natural gas facilities, and EV charging facilities are shown in Table 8. Among them, the total variable cost is the discounted value of all variable costs during the planning period, and the total cost is the total investment cost and the total variable cost minus the residual value. It can be seen from the table that the cost of power components, TCe, still accounts for a large proportion, reaching $175,235,900$ US dollars, and the cost of natural gas facilities TC8s has also reached 95,341,300 US dollars. The investment in the transportation network is relatively small, accounting for only the overall total cost. 8.03\% of TColal. In the cost item TCe, the cost of distributed gas and DCHP is relatively high, mainly due to the larger installed capacity, which is related to the higher fuel cost compared to DREG. If further analysis, this is related to SUME is a relatively independent self-balancing system, which needs to maintain the reliability of the system itself and meet the thermal load. The high reliability of the system requires the configuration of gas-fired units that can produce flexibly. DCHP alleviates the problem of relying solely on electric heating or burning fossil energy.

Table 8. The overall cost of the types of facilities in the planning results.

\begin{tabular}{|c|c|c|c|c|c|c|c|c|c|}
\hline $\begin{array}{c}\text { Type of } \\
\text { facility }\end{array}$ & $\begin{array}{c}\text { Wind } \\
\text { power }\end{array}$ & PV & $\begin{array}{c}\text { Distribut } \\
\text { ed gas }\end{array}$ & DCHP & $\begin{array}{c}\text { Biomass } \\
\text { power } \\
\text { generation }\end{array}$ & $\begin{array}{c}\text { Energy } \\
\text { storage } \\
\text { unit }\end{array}$ & $\begin{array}{c}\text { Transmissi } \\
\text { on line }\end{array}$ & $\begin{array}{c}\text { Natural gas } \\
\text { facilities }\end{array}$ & $\begin{array}{c}\text { EV charging } \\
\text { facilities }\end{array}$ \\
\hline $\begin{array}{c}\text { Total } \\
\text { investment } \\
\text { cost }\end{array}$ & 3202.5 & 2537.17 & 1590.55 & 1320.23 & 2432.9 & 442.47 & 740.87 & 7922.11 & 1932 \\
\hline $\begin{array}{c}\text { Total variable } \\
\text { cost }\end{array}$ & 373.3 & 390.09 & 4055.82 & 2177.24 & 822.36 & 580.83 & 999.31 & 3564.9 & 947.64 \\
\hline Total cost & 3147.05 & 2634.38 & 4798.94 & 3042.6 & 2928.92 & 971.69 & 1652.05 & 9534.13 & 2505.29 \\
\hline
\end{tabular}

\section{CONCLUDING REMARKS}

This paper studies the green energy Internet planning model, takes power system planning as the main module, considers the requirements and constraints of natural gas network and transportation network construction, and uses the energy hub model to analyse the energy transmission and conversion relationship between different networks, so as realize comprehensive energy system planning for power system, natural gas network, and transportation network. To verify the effectiveness of the proposed 
PMIES planning method, an improved Garver test system is used for simulation.

As the load of each node increases, six power nodes have newly installed capacity, as shown in Figures 2 and 3. Among them, nodes 1,3, 4, and 6 are equipped with gas generators and DCHP, so they are connected to gas transmission. The pipe is connected to it.

For the two modules of natural gas network and electric vehicle charging facilities, some intermediate data were extracted.

The average flow of the channels between the natural gas nodes, the pressure of each node in the natural gas network, and the configuration of the charging devices of each node in the transportation network are extracted. We performed a data simulation on planning modelling and found that the results obtained are consistent with our planning model.

\section{Acknowledgments}

This work has been supported by the National Key Research and Development Program No.2018YFB2100100, Postdoctoral Science Foundation of Yunnan Province, Science Foundation of Yunnan Province No.202101AT070167, Project of the Yunnan Provincial Department of Education scientific research fund No. 2019J0010, DongLu Young and Middle-aged backbone Teachers Project of Yunnan University, Open Foundation of Key Laboratory in Software Engineering of Yunnan Province under Grant No.2020SE311, Science and Technology Project of Yunnan Power Grid Co., Ltd No.YNKJXM20180092 and YNKJXM20190639.

\section{References}

1. B. Miao et al., "Day-Ahead Energy Trading Strategy of Regional Integrated Energy System Considering Energy Cascade Utilization," in IEEE Access, vol. 8, pp. 138021-138035, (2020)

2. L. Ji, L. Wang, C. Liao and S. Li, "Simultaneous Wireless Power and Bidirectional Information Transmission With a Single-Coil, Dual-Resonant Structure," in IEEE Trans Ind Electron, vol. 66, no. 5, pp. 4013-4022, May (2019)

3. A. Azizivahed et al., "Energy Management Strategy in Dynamic Distribution Network Reconfiguration Considering Renewable Energy Resources and Storage," in IEEE Trans. Sustainable Energy, vol. 11, no. 2, pp. 662-673, April (2020)

4. J. Wang et al., "Two-Stage Integrated Electricity and Heat Market Clearing With Energy Stations," in IEEE Access, vol. 7, pp. 44928-44938, (2019)

5. L. Cheng, T. Yu, H. Jiang, S. Shi, Z. Tan and Z. Zhang, "Energy Internet Access Equipment Integrating Cyber-Physical Systems: Concepts, Key Technologies, System Development, and Application Prospects," in IEEE Access, vol. 7, pp. 23127-23148, (2019)

6. Z. Liu, M. Zeng, H. Zhou and J. Gao, "A Planning
Method of Regional Integrated Energy System Based on the Energy Hub Zoning Model," in IEEE Access, vol. 9, pp. 32161-32170, (2021)

7. W. Wang, L. Liu, J. Liu and Z. Chen, "Energy management and optimization of vehicle-to-grid systems for wind power integration," in CSEE Journal of Power and Energy Systems, vol. 7, no. 1, pp. 172180, Jan. (2021)

8. Z. Zhao, H. Zhou, L. Qi, L. Chang and M. Zhou, "Inductive Representation Learning via CNN for Partially-Unseen Attributed Networks," in IEEE Trans. Netw. Sci. Eng., 8, no. 1, pp. 695-706 (2021)

9. F. Zhang et al., "Understanding WeChat User Preferences and "Wow" Diffusion," in IEEE Trans Knowl Data Eng (2021) 